\title{
O ALCANCE DA COLABORAÇÃO NO DEVER DE FUNDAMENTAÇÃO DAS DECISÕES JUDICIAIS - ANÁLISE DO ART. 489, § 1º, IV, DO CPC $/ 2015^{1}$
}

\section{THE REACH OF COLLABORATION ON THE DUTY OF THE FOUNDATION OF JUDICIAL DECISIONS - ANALYSIS OF ART. 489, § $1^{\circ}$, IV, CPC/2015}

Cidiclei Veiga Klein Especialista em Direito Civil e Processual Civil pelo Centro Universitário Curitiba (UNICURITIBA). Assessor Jurídico (efetivo) do Tribunal de Justiça do Estado do Paraná. Curitiba/PR. E-mail: cidiklei@gmail.com

Francisco Cardozo Oliveira Pós-Doutor pela UFSC e Doutor pela UFPR. Juiz de Direito do Tribunal de Justiça do Estado do Paraná e Professor de Direito Civil no Centro Universitário Curitiba (UNICURITIBA). Curitiba/PR. E-mail: xikocardozo@msn.com

RESUMO: Pretende-se estabelecer, primeiramente, um esboço do desdobramento histórico do processo civil, com base na perspectiva da Escola de Processo Civil de São Paulo, abordando brevemente as fases sincretista, conceitualista e instrumentalista. Em seguida, ingressa-se no estudo da colaboração, visualizada como modelo de processo e também como princípio orientador. Por fim, procura-se estabelecer algumas premissas acerca do alcance do dever de fundamentação das decisões judiciais, para então relacionar o seu adequado cumprimento, sobretudo com base no disposto pelo art. $489, \S 1^{\circ}$, IV, do CPC/2015, à prévia observância da colaboração.

PALAVRAS-CHAVE: Processo Civil; Colaboração; Princípio; Fundamentação das Decisões Judiciais.

\footnotetext{
${ }^{1}$ Artigo recebido em 10/10/2018 e aprovado em 27/03/2019.
} 
ABSTRACT: It is intended to establish, first, an outline of the historical unfolding of the civil process, based on the perspective of the School of Civil Procedure of São Paulo, briefly addressing the syncretist, conceptual and instrumentalist phases. It then enters into the study of collaboration, visualized as a process model and also as guiding principle. Lastly, it is sought to establish some premises about the scope of the duty to justify judicial decisions, and then to relate their proper accomplishment, especially based on the provisions of art. $489, \S 1^{\circ}$, IV, of $\mathrm{CPC} / 2015$, to the prior observance of the collaboration.

KEYWORDS: Civil Process; Collaboration; Principle; Foundation of Judicial Decisions.

\section{INTRODUÇÃO}

A partir do exame da evolução histórica do estudo da ciência processual civil, é possível perceber que, na atual fase, sobretudo com a edição do novo Código de Processo Civil de 2015, o processo civil brasileiro encontra-se estruturado sob um modelo cooperativo, especialmente pelo fortalecimento do contraditório, evidenciando a natureza dialética da relação processual. Pautada nos deveres de esclarecimento, prevenção, debate e auxílio, a função de conduzir o processo atribuída ao juiz, hoje, não se confunde com a atuação de mero expectador ou de guardião do processo, vigente nos modelos isonômico e assimétrico, respectivamente. Na contemporaneidade, a despeito de se conferir ainda ao juiz a direção do processo, exige-se dele um constante diálogo com as partes, que têm sua participação valorizada na busca pela celeridade e efetividade da tutela jurisdicional, formando-se uma verdadeira comunidade de trabalho dentro do processo.

Justifica-se a análise na perspectiva de identificar o alcance do dever de colaboração na fundamentação das decisões judiciais.

Coloca-se como problema da análise evidenciar, ao longo do trabalho, a relação entre a adequada fundamentação das decisões judiciais e a correta observância do contraditório, informado pelo dever de colaboração, e seu desdobramento que exige do magistrado o exame de todos os argumentos deduzidos pelas partes em suas manifestações, sempre que eles tiverem aptidão para infirmar a conclusão adotada pelo órgão julgador.

Para alcançar este escopo, propõe-se o exame da evolução histórica do estudo da 
Revista Eletrônica de Direito Processual - REDP.

Rio de Janeiro. Ano 13. Volume 20. Número 2. Maio a Agosto de 2019

Periódico Quadrimestral da Pós-Graduação Stricto Sensu em Direito Processual da UERJ

Patrono: José Carlos Barbosa Moreira (in mem.). ISSN 1982-7636. pp. 47-73

www.redp.uerj.br

ciência processual civil, com base na perspectiva da Escola Paulista de Processo Civil, desde o sincretismo até a atual fase do instrumentalismo, abordando a questão da colaboração no processo enquanto modelo e princípio, conforme proposto por Daniel Mitidiero, e traçando a sua influência sobre o adequado cumprimento do dever de fundamentação das decisões judiciais, sobretudo a partir do que dispõe o art. $489, \S 1^{\circ}$, do Código de Processo Civil de 2015.

Adota-se o método dedutivo, apoiado em material bibliográfico.

\section{RECONSTRUÇÃO HISTÓRICA DA CIÊNCIA PROCESSUAL CIVIL}

Mostra-se necessário elaborar uma reconstrução histórica e normativa da ciência processual civil, de modo a situar, na atualidade, o papel do dever de colaboração e sua função na fundamentação das decisões judiciais. De acordo com Dinamarco e Carrilho Lopes $^{2}$, o estudo do processo civil na sua história aponta para a existência de três fases metodológicas: (a) sincretismo - vigente a partir da sua origem; (b) autonomista ou conceitual - a partir de meado do século XIX; e (c) teleológica ou instrumentalista vigente na atualidade.

\subsection{SINCRETISMO PROCESSUAL E A DEFINIÇÃO DE AÇÃO}

$\mathrm{Na}$ fase do sincretismo, os conhecimentos eram obtidos por meio de critérios práticos e estudados com base em parâmetros essencialmente exegéticos, sem uma elaboração estável dos institutos processuais e, tampouco, uma sistematização coerente entre eles, os quais normalmente eram abordados por romanistas e civilistas ${ }^{3}$. Nesta fase, o processo era tratado como mero procedimento, pois o definiam como uma sucessão de atos, nada mencionando sobre a relação jurídica havida entre seus sujeitos ${ }^{4}$.

Neste primeiro momento, portanto, não havia uma consciência sobre a autonomia da ciência processual, os institutos processuais e o próprio processo eram abordados no mesmo plano dos institutos de direito material, como se deles fossem parte integrante. Essa noção foi delineada em uma afamada manifestação de um processualista romano do século

\footnotetext{
2 DINAMARCO, Cândido Rangel; CARRILHO LOPES, Bruno Vasconcelos. Teoria Geral do Novo Processo Civil. São Paulo: Malheiros Editores, 2016. p. 17.

${ }^{3}$ DINAMARCO, Cândido Rangel. Fundamentos do Processo Civil Moderno. São Paulo: Editora Revista dos Tribunais, 1986. p. 12.

${ }^{4}$ DINAMARCO e CARRILHO LOPES, 2016, p. 18.
} 
Revista Eletrônica de Direito Processual - REDP.

Rio de Janeiro. Ano 13. Volume 20. Número 2. Maio a Agosto de 2019

Periódico Quadrimestral da Pós-Graduação Stricto Sensu em Direito Processual da UERJ

Patrono: José Carlos Barbosa Moreira (in mem.). ISSN 1982-7636. pp. 47-73

www.redp.uerj.br

XIX, Vittorio Scialoja, de acordo com a qual "aquele que propõe a ação está a exercer o próprio direito, justamente porque a defesa do direito é um elemento constitutivo dele próprio" 5 .

Decorre deste momento histórico, a propósito, conforme afirma Bedaque ${ }^{6}$, a definição de ação como sendo o direito que alguém possui de buscar, em juízo, o que lhe é devido pelo descumprimento do seu direito material subjetivo.

\subsection{CONCEITUALISMO NO PROCESSO}

A construção científica do processo se deu a partir da denominada fase autonomista $^{7}$ ou conceitualista, por meio da obra de Oskar Von Bülow, na qual se discorria acerca das exceções e pressupostos processuais, publicada em 1868, na Alemanha ${ }^{8}$.

Nesta fase, os processualistas se conscientizaram da autonomia científica do processo, percebendo que ele não constituía uma simples forma de exercício dos direitos. Superou-se, assim, a ideia, até então cultivada com base na clássica conceituação privatista da ação, de que o processo era inerente ao próprio direito subjetivo material (daí decorrendo a teoria imanentista ou civilista da ação), ou o próprio direito que, uma vez infringido, é dotado de forças para perseguir sua reparação perante o judiciário 9 .

Neste momento de surgimento da ciência processual é que foram formuladas as grandes teorias acerca de jurisdição, ação, defesa e processo, evoluindo-se da pura técnica para a ciência, do simples procedimento para o processo $^{10}$.

Ainda nesta segunda fase, foi editado, no Brasil, em 1939, o primeiro Código de Processo Civil de âmbito nacional. Até então, como explica Dinamarco ${ }^{11}$, vigia um sistema pluralista, pautado na existência de um código próprio para cada Estado da Federação ${ }^{12}$.

\footnotetext{
${ }^{5}$ Apud DINAMARCO e CARRILHO LOPES, 2016, p. 18.

6 BEDAQUe, José Roberto dos Santos. Direito e Processo: influência do direito material sobre o processo. 2. ed. São Paulo: Malheiros Editores, 1995. p. 22.

${ }^{7}$ Ibid., p. 13.

${ }^{8}$ DINAMARCO, 1986, p. 12.

${ }^{9}$ DINAMARCO e CARRILHO LOPES, op. cit., p. 19.

${ }^{10}$ BEDAQUE, op. cit, p. 23.

${ }^{11}$ Op. cit., p. 4.

12 Antes dos Códigos Estaduais, vigia o Regulamento 737, o qual havia sucedido as Ordenações Portuguesas. Tal Regulamento era considerado, por alguns, como um relevante instrumento normativo da sua época, mas, para outros, era o atestado de ignorância dos juristas do seu tempo, uma vez que completamente defasado em relação às novas colocações científicas surgidas com a obra de Von Bülow (DINAMARCO, 1986, p. 21).
} 
Revista Eletrônica de Direito Processual - REDP.

Rio de Janeiro. Ano 13. Volume 20. Número 2. Maio a Agosto de 2019

Periódico Quadrimestral da Pós-Graduação Stricto Sensu em Direito Processual da UERJ

Patrono: José Carlos Barbosa Moreira (in mem.). ISSN 1982-7636. pp. 47-73 www.redp.uerj.br

Para Dinamarco ${ }^{13}$, os códigos estaduais (ressalva do autor aos códigos de São Paulo e da Bahia) eram marcados por uma pobreza científica, decorrente da própria forma de sistema adotada (pluralista), além da falta de atualização metodológica da doutrina daquela época, uma vez que aqui ainda não haviam chegado os ares da nova ciência processual que, originada na obra de Von Bülow, evoluiu nas produções científicas de Wach, Hellwig e Chiovenda.

Mesmo o Código de Processo Civil de 1939, com uma ambição pedante, até certo ponto, de consubstanciar-se em um instrumento alinhado às modernas propensões do seu tempo (mormente as norte-americanas, o que se pode constatar a partir da Exposição de Motivos do Min. Francisco Campos), foi um diploma marcado por visíveis defeitos, especialmente em razão da indiferença com as relevantes conquistas mundiais no desenvolvimento da ciência processual - a exemplo da regulamentação conferida a institutos como competência, recursos, execução, etc ${ }^{14}$.

A despeito desta pobreza científica da época, no entanto, Dinamarco ${ }^{15}$ assinala a existência de brilhantes processualistas brasileiros, citando, da tradicional Escola de São Paulo, João Monteiro, que no começo do século passado já argumentava acerca da teoria abstrata da ação, e também João Mendes Júnior, o qual discorreu sobre as regras do devido processo legal, chegando, inclusive, a sugerir o estudo do processo civil a partir da interpretação das normas extraídas da Constituição (posição metodológica em plena conformidade com a atual proposição do direito italiano e brasileiro).

Foi, contudo, apenas com a chegada de Enrico Tullio Liebman ao Brasil que o estudo do processo civil brasileiro teve uma efetiva evolução. Liebman, que foi aluno de Chiovenda na Universidade de Roma, herdou de seu mestre o interesse pelo conhecimento da história e o estudo comparado do direito processual civil, transmitindo aos leitores de suas obras conhecimento sólido acerca dos doutrinadores clássicos e modernos, ao qual acrescentou suas descobertas e criações ${ }^{16}$.

Alfredo Buzaid, um dos discípulos de Liebman, com relevantes informações históricas e comparativas, sobretudo leais à linha de pensamento do moderno processo

\footnotetext{
13 1986, p. 5.

14 Dinamarco, Cândido Rangel. A Reforma do Código de Processo Civil. São Paulo: Malheiros Editores, 1995. p. 21.

15 Op. cit., p. 5.

${ }^{16}$ DINAMARCO, op. cit., p. 7.
} 
Revista Eletrônica de Direito Processual - REDP.

Rio de Janeiro. Ano 13. Volume 20. Número 2. Maio a Agosto de 2019

Periódico Quadrimestral da Pós-Graduação Stricto Sensu em Direito Processual da UERJ

Patrono: José Carlos Barbosa Moreira (in mem.). ISSN 1982-7636. pp. 47-73

www.redp.uerj.br

civil, foi o protagonista do Código de Processo Civil de $1973^{17}$. Este diploma, apesar de ter sido elaborado com o manifesto escopo de representar, realmente, uma nova estrutura normativa para o processo civil, e não somente simples retoques à codificação anterior, ainda refletia a forma tradicional de pensar o processo, de modo que não se revestia da necessária aptidão para impor significativas mudanças ao sistema então vigente ${ }^{18}$.

Conforme conhecida lição de Chiovenda, reproduzida por Dinamarco ${ }^{19}$, o que diferencia significativamente um sistema de outro, no tempo e no espaço, são os princípios que, adotados por um, não o são pelo outro, ou então a maneira diversificada pela qual cada um deles acolhe determinados princípios. Os princípios e linhas fundamentais que nortearam o Código de Processo Civil de 1973 foram os mesmos da codificação de 1939.

Cumpre salientar, no entanto, que, especialmente em decorrência do grande esforço de Enrico Tullio Liebman, e do grupo de estudiosos da Escola Processual de São Paulo, por aquele diretamente influenciado, o Código de Processo Civil de 1973 teve o mérito de, ao menos, aperfeiçoar os institutos processuais a partir dos maiores conhecimentos incorporados à cultura brasileira da década de 1970, além de introduzir novos institutos como o julgamento antecipado do mérito, o chamamento ao processo, o recurso adesivo, etc $^{20}$.

Conforme Dinamarco ${ }^{21}$, no entanto, “o Código Buzaid foi uma obra de seu tempo e do estado da doutrina brasileira de quando foi editado". Não se estava atento, já naquela época, às profundas mudanças que vinham ocorrendo no estudo da ciência processual, sobretudo no âmbito da efetividade do processo, bandeira esta hasteada em regiões da Europa.

De acordo com Mitidiero ${ }^{22}$, o Código de Processo Civil de 1973 foi concebido sob uma persuasiva postura científica devido ao clima de tecnicidade predominante à época, mercê da até então recente concepção do direito processual como ciência autônoma, o que de certo modo acabou por afastar excessivamente o direito processual do direito material e da realidade social. Quanto mais claros ficavam os conceitos em torno dos institutos processuais e mais desenvolvidas as suas teorias, mais aumentava a distância do processo

\footnotetext{
${ }^{17}$ Ibid., p. 9.

${ }^{18}$ DINAMARCO, 1995, p. 22.

${ }^{19}$ Ibid., p. 23.

${ }^{20}$ DINAMARCO, 1995, p. 22

${ }^{21}$ Loc. cit.

${ }^{22}$ MITIDIERO, Daniel. Colaboração no Processo Civil - Pressupostos Sociais, Lógicos e Éticos. 3. ed. São Paulo: Editora Revista dos Tribunais, 2015. p. 33-34.
} 
em relação aos seus escopos essenciais.

Foi a partir desta percepção, de que havia a necessidade de ser retomada a finalidade substancial do processo, que se chegou ao final da segunda fase metodológica do estudo do processo, ganhando credibilidade, a partir daí, a tese de que o direito processual civil deveria ser visto como um instrumento de efetivação dos direitos.

\subsection{INSTRUMENTALISMO E EFETIVIDADE DO PROCESSO}

$\mathrm{Na}$ terceira fase de estudo da ciência processual (teleológica ou instrumentalista), conforme sistematização de Dinamarco e Carrilho Lopes ${ }^{23}$, a doutrina internacional da ciência processual civil foi marcada, a partir da segunda metade do século XX, por relevantes mudanças.

O considerável esforço dos defensores da ideia da "efetividade do processo" permitiu o desenvolvimento do pensamento sobre a utilidade de se analisar o processo como algo dotado de funções institucionais bem delineadas, e que tem por dever observar seus escopos, sob pena de não ser adequado e, também, não gozar de legitimidade social ${ }^{24}$.

Conforme Dinamarco ${ }^{25}$, dentre as iniciativas metodológicas observadas neste período, vale menção às de Mauro Cappelletti e de Vitorio Denti, cujos discípulos e seguidores, tanto na Itália, quanto em toda a Europa continental e em algumas regiões da América, constituem um grupo atualmente muito coerente em torno do conceito que se ajustou chamar "acesso à justiça".

As alterações desta época, que impactaram a forma de pensar e aplicar o processo civil, progrediram com base em algumas relevantes "ondas renovatórias", de acordo com o que ressalta Dinamarco ${ }^{26}$, a exemplo da facilitação do acesso ao processo àqueles menos afortunados e a defesa de direitos e interesses coletivos, com a simplificação do processo, a fim de torná-lo mais participativo e menos burocrático, e, acima de tudo, propondo-se um processo menos preocupado com conceitos ou observância de formas irrelevantes, e mais concentrado na obtenção dos resultados que dele se esperam.

O Direito Processual Civil Brasileiro mostrou-se receptivo a estas novas tendências, seja pelo significativo número de estudiosos que a elas se filiaram, seja pelas várias

\footnotetext{
23 2016, p. 17.

${ }^{24}$ DINAMARCO, op. cit., p. 19.

25 1995, p. 19.

${ }^{26}$ Ibid, p. 20.
} 
Revista Eletrônica de Direito Processual - REDP.

Rio de Janeiro. Ano 13. Volume 20. Número 2. Maio a Agosto de 2019

Periódico Quadrimestral da Pós-Graduação Stricto Sensu em Direito Processual da UERJ

Patrono: José Carlos Barbosa Moreira (in mem.). ISSN 1982-7636. pp. 47-73

www.redp.uerj.br

reverberações que tais proposições doutrinárias ocasionaram, e ainda vêm acarretando, em nosso ordenamento positivo ${ }^{27}$.

Coincide com esta época, nos idos das décadas de sessenta e setenta do século passado, o surgimento no Brasil de uma nova geração de processualistas, especialmente preocupados com a efetividade do processo e adotando uma postura constitucionalista, os quais enfatizam a força normativa da constituição ${ }^{28}$, de onde se extraem os fundamentos do sistema processual ${ }^{29}$.

\subsection{PROCESSO CIVIL CONSTITUCIONAL - PRINCÍPIOS E GARANTIAS}

Importante destacar que, para parte da doutrina, a visão do processo segundo às normas constitucionais seria uma nova fase metodológica, posterior ao instrumentalismo, denominada, por alguns, de "Neoprocessualismo" e, por outros, de "Formalismo Valorativo", conforme ressalta Mitidiero ${ }^{30}$. Segue-se, aqui, no entanto, a corrente que defende ser a interpretação do processo de acordo com as balizas estabelecidas pela Constituição da República apenas um aperfeiçoamento do instrumentalismo, sem quebra de paradigma a justificar o surgimento de uma nova metodologia de estudo do processo.

Fala-se, hoje, sobre a jurisdição constitucional, que reflete diretamente a instrumentalidade do processo à ordem social econômica e política consubstanciada na Constituição e nas leis. Nas palavras de João Mendes Jr - que já no início do século passado pregava a ideia de interpretação das normas processuais de acordo com os fundamentos extraídos da Constituição -, o processo constitui um meio, não apenas para chegar ao objetivo imediato - julgamento -, mas também para alcançar o fím longínquo concernente à segurança constitucional dos direitos e da execução das leis ${ }^{31}$.

Temos hoje um modelo constitucional do processo civil brasileiro, constituído

\footnotetext{
${ }^{27}$ DINAMARCO, loc. cit.

28 De acordo com CAMBI (2006, p. 662-683), citando Luis Roberto Barroso, a força normativa da constituição representa uma das grandes conquistas obtidas com o Neoconstitucionalismo, ao lado da ampliação da jurisdição Constitucional e da construção de uma nova dogmática relacionada à interpretação constitucional. Como afirma CANOTILHO (1995, p. 183), a Constituição não pode consistir apenas em uma carta de intenções políticas, desprovida de caráter imperativo no ordenamento em que inserida. As regras e princípios extraídos da Constituição precisam ter sua carga normativa reconhecida, a fim de que possam reger jurídica e efetivamente as relações sociais, gerando segurança a expectativas de comportamentos.

${ }^{29}$ DINAMARCO e CARRILHO LOPES, 2016, p. 35-36.

${ }^{30} 2015, \mathrm{p} 48$.

${ }^{31}$ DINAMARCO, 1996, p. 27.
} 
Revista Eletrônica de Direito Processual - REDP.

Rio de Janeiro. Ano 13. Volume 20. Número 2. Maio a Agosto de 2019

Periódico Quadrimestral da Pós-Graduação Stricto Sensu em Direito Processual da UERJ

Patrono: José Carlos Barbosa Moreira (in mem.). ISSN 1982-7636. pp. 47-73

www.redp.uerj.br

pelas normas, princípios e garantias decorrentes do direito processual constitucional, e especialmente por aquelas normas que conferem a tutela constitucional do processo $^{32}$.

Este modelo constitucional do processo civil brasileiro, conforme DINAMARCO e CARRILHO LOPES ${ }^{33}$, possui características marcantes, que podem ser sintetizadas na (a) unidade da jurisdição estatal - visto que no Brasil apenas o Poder Judiciário a exerce, inexistindo aqui o denominado contencioso administrativo; (b) na independência do Poder Judiciário frente aos demais poderes constituídos - Executivo e Legislativo; (c) na dualidade das técnicas do controle de constitucionalidade de leis e atos normativos do Poder Público - concentrado ou difuso; e (d) na oferta de um complexo de garantias que compõem a tutela constitucional do processo, dentre as quais se destacam a igualdade (CRFB/88, art. $5^{\circ}$, caput, c/c art. $3^{\circ}$, IV), a inafastabilidade da jurisdição (CRFB/88, art. $5^{\circ}$, XXXV), a existência de um juiz natural (CRFB/88, art. 5, XXXVII e LIII), o contraditório (CRFB/88, art. $\left.5^{\circ}, \mathrm{LV}\right)$, a inadmissibilidade das provas ilícitas (CRFB/88, art. 5, LVI), a publicidade dos atos processuais e a exigência de todas as decisões judiciais (CRFB/88, art. 93, IX, c/c art. $\left.5^{\circ}, \mathrm{LIV}\right)$. Estas características extraídas do texto constitucional bem permitem definir o perfil democrático do atual modelo de processo vigente no país.

A propósito, com base em Mitidiero $^{34}$, vale o destaque de que muitos destes princípios, garantias e direitos fundamentais elencados no texto da Carta Política encontram-se textualmente previstos nas normas do novo Código de Processo Civil de 2015, a evidenciar ainda mais este enfoque do processo na esteira do que dispõem as matrizes constitucionais, a exemplo da inafastabilidade da jurisdição, a razoável duração do processo, a liberdade, a igualdade, a participação, a segurança, a justiça, a publicidade e a motivação, contempladas nos arts. $1^{\circ}, 3^{\circ}, 4^{\circ}, 7^{\circ}, 8^{\circ}, 9^{\circ}, 10$ e 11 da nova codificação.

\section{COLABORAÇAO NO PROCESSO CIVIL}

A forma de pensar o processo civil hoje, com os aportes advindos da teoria do direito e do direito constitucional, deve-se à necessária preocupação com as determinantes sociais da nossa época, rememorando-se sempre a essência do processo civil e sua

\footnotetext{
${ }^{32}$ DINAMARCO e CARRILHO LOPES, 2016, p. 38.

${ }^{33}$ Loc. cit.

${ }^{34}$ Op cit., p. 50.
} 
fundamental proximidade com a sociedade ${ }^{35}$.

Neste cenário, defende Mitidiero ${ }^{36}$, não se pode mais deixar a jurisdição como sendo o cerne da teoria do processo civil, visto que a manutenção deste pensamento representaria uma visão deturpada do fenômeno processual, desprezando-se a dimensão substancialmente participativa consequente da democracia alcançada pelo direito constitucional contemporâneo.

Já vem das nossas Ordenações Afonsinas (depois reprisado pelas Manuelinas e Filipinas) a noção de que, para a estrutura do juízo, "sao necessarias três pessoas, o Juiz, Autor, e Reo; o Autor pera demandar, e o Reo pera se defender, e o Juiz pera julguar" (Livro III, Título XX, $\S 1^{\circ}$ ). É dizer, o processo constitui uma obra de três pessoas (iudicium est actum trium personarum"). Com isso, obviamente, não se nega a relevância que deve ser atribuída à jurisdição no âmbito do processo. Mas se ressalta a importância, outrossim, que a condição das partes possui para o bom andamento do processo. A repartição adequada das tarefas do processo encerra um legítimo equilíbrio entre as posições jurídicas ocupadas pelas partes e pelo juiz. Esta a razão para o Código de Processo Civil de 2015 dispor acerca da colaboração em seu art. $6^{\circ}$, no capítulo reservado às suas normas fundamentais ${ }^{37}$.

A alocação do processo no epicentro da teoria geral do processo civil contemporâneo evidencia a natureza especialmente controvertida apresentada pelo direito moderno, para cuja elucidação se necessita da convergência dos argumentos de todos aqueles que integram o processo. Neste contexto, aliás, a transição da jurisdição para o processo equivale, sob uma análise lógico-jurídica, à transição da lógica apodítica à lógica do debate: "do monólogo jurisdicional ao diálogo judiciário". Não é coincidência o novo Código de Processo Civil ter contemplado, a par da colaboração (CPC/2015, arts. $9^{\circ}$ e 10), a necessidade de uma rigorosa obediência ao contraditório, seja pelo juiz, seja pelas partes $^{38}$.

Neste contexto, a propósito, a democracia participativa, reputada direito fundamental de quarta dimensão ${ }^{39}$, aconselha a configuração do processo como um

\footnotetext{
${ }^{35}$ MITIDIERO, 2015, p. 45.

36 Loc. cit.

${ }^{37}$ MITIDIERO, Ibid., p. 45-46.

${ }^{38}$ MITIDIERO, 2015, p. 46-47.

${ }^{39}$ Cf. BONAVIDES, Paulo. Teoria Constitucional da Democracia Participativa. São Paulo: Malheiros Editores, 2001. p. 29.
} 
Revista Eletrônica de Direito Processual - REDP.

Rio de Janeiro. Ano 13. Volume 20. Número 2. Maio a Agosto de 2019

Periódico Quadrimestral da Pós-Graduação Stricto Sensu em Direito Processual da UERJ

Patrono: José Carlos Barbosa Moreira (in mem.). ISSN 1982-7636. pp. 47-73

www.redp.uerj.br

ambiente favorável ao exercício direto de poder pelo povo. Nestes termos, fomenta-se a cooperação no processo, incorporando-se a posição jurídica de cada parte, com o escopo de transformar este instrumento em um verdadeiro e democrático ponto de encontro e efetivação de direitos fundamentais $\left(\mathrm{CPC} / 2015 \text {, arts. } 1^{\circ}, 7^{\circ}, 9^{\circ} \text { e } 10\right)^{40}$.

Dentre as normas fundamentais consagradas na nova codificação, vale destaque, para o presente trabalho, aquela constante do seu art. $6^{\circ}$, segundo a qual "todos os sujeitos do processo devem cooperar entre si para que se obtenha, em tempo razoável, decisão de mérito justa e efetiva". Se compreendido bem o seu sentido, pode-se constatar que se trata de uma norma de especial importância, pois ao mesmo tempo em que busca identificar o processo civil brasileiro a partir de um "modelo cooperativo", também pretende determinar o seu funcionamento a partir de um princípio, o da "colaboração"41.

\subsection{COLABORAÇÃO COMO MODELO DE PROCESSO}

A cooperação no processo civil representa um modelo que tem por escopo a divisão equânime de tarefas entre as posições jurídicas ocupadas pelo juiz e pelas partes, instituindo, dessa forma, uma verdadeira comunidade de trabalho, na qual se valoriza o esforço conjunto desenvolvido pelos sujeitos processuais ${ }^{42}$.

Cuida-se de um modelo de processo construído com base em pressupostos culturais - sociais, lógicos e éticos -, e que retrata um avanço se comparado com os modelos dispositivo e inquisitório. Neste particular, para Mitidiero ${ }^{43}$, mostra-se mais adequado falar-se em modelos isonômico e assimétrico, ao invés de "dispositivo" e "inquisitório", porquanto estes seriam modelos que representam apenas a perspectiva relacionada às posições jurídicas dos sujeitos processuais, no que concerne à gestão do processo, deixando de lado outros aspectos importantes de comparação. Além do mais, o processo cooperativo preserva traços tanto do modelo "dispositivo" (a exemplo da possibilidade de formalização do julgamento pela incidência das regras que dispõem sobre o ônus da prova - CPC/2015, art. 373) quanto do "inquisitório" (a exemplo da possibilidade de o juiz instruir o processo de ofício - CPC/2015, art. 370).

\footnotetext{
${ }^{40}$ MITIDIERO, Ibid, p. 47.

${ }^{41}$ MITIDIERO, Ibid., p. 52.

${ }^{42}$ MITIDIERO, loc. cit.

${ }^{43}$ Ibid., p. 53.
} 
Revista Eletrônica de Direito Processual - REDP.

Rio de Janeiro. Ano 13. Volume 20. Número 2. Maio a Agosto de 2019

Periódico Quadrimestral da Pós-Graduação Stricto Sensu em Direito Processual da UERJ

Patrono: José Carlos Barbosa Moreira (in mem.). ISSN 1982-7636. pp. 47-73 www.redp.uerj.br

A comparação entre os modelos de processo isonômico, assimétrico e colaborativo é possível por meio do exame dos pressupostos (todos de natureza cultural) sociais, lógicos e éticos.

\subsubsection{Pressupostos Sociais}

Os pressupostos sociais permitem o exame comparativo entre formas de organização da sociedade e os seus reflexos sobre a figura do magistrado. Vale dizer, a partir da noção de que a prática jurídica pode ser caracterizada em razão dos traços da história de seu tempo, é possível concluir que a cada estrutura de organização social equivalha a um comportamento emprestado à magistratura ${ }^{44}$.

No âmbito do modelo isonômico, inexiste uma hierarquização na estruturação da sociedade. Não há, aqui, distinção entre o Estado, a sociedade civil e o cidadão, colocando o magistrado no mesmo patamar que as partes. Exemplos deste modelo podem ser extraídos das experiências políticas gregas e italianas (período medieval) ${ }^{45}$.

No modelo assimétrico, por sua vez, valendo-se aqui das experiências do processo civil romano (da cognitio extra ordinem) e do processo civil prussiano do Setecentista, parte-se de uma clara diferenciação entre indivíduo, sociedade e Estado, fixando-se uma relação hierarquizada entre governantes e governados. Neste modelo de processo, o magistrado coloca-se acima das partes, nascendo daí a alteridade ${ }^{46}$.

Já o modelo de processo pautado na colaboração tem suas bases extraídas de outros fundamentos. Não se desconhece que ainda aqui existe a distinção entre indivíduo, sociedade e Estado. Ocorre, no entanto, que a relação presente entre eles é estabelecida de maneira bem diversa daquela havida no processo assimétrico ${ }^{47}$.

Na situação brasileira, a Constituição, ao instituir a República Federativa do Brasil como um Estado Democrático de Direito - submetendo-o, portanto, ao Direito, e valorizando a participação social na sua gestão -, enaltece o espírito cooperativo ao fixar como um dos fundamentos da República a dignidade da pessoa humana (art. $1^{\circ}$, III), e estabelecer dentre outros objetivos fundamentais a construção de "uma sociedade livre,

\footnotetext{
${ }^{44}$ MITIDIERO, 2015, p. 54.

${ }^{45}$ MITIDIERO, Ibid., p. 55.

${ }^{46}$ MITIDIERO, Ibid., p. 57-58.

${ }^{47}$ MITIDIERO, 2015, p. 63.
} 
justa e solidária" (art. $\left.3^{\circ}, \mathrm{I}\right)^{48}$.

Este perfil atribuído ao Estado pela sociedade por meio da ordem Constitucional possui inegável influência no atual modelo de juiz, alocando-o a uma posição que, ao mesmo tempo, permite-lhe participar de forma paritária com as partes na relação dialética do processo, e, também, em situação de superioridade, quando precisa proferir decisões sobre as questões formais e meritórias do processo. Em suma, o magistrado ocupa uma dupla função no processo: paritária quanto ao diálogo estabelecido com as partes, e assimétrica em relação às decisões que profere ${ }^{49}$.

A isonomia deste modelo processual, considerada a dupla função atribuída ao magistrado, ocorre no sentido de que, conquanto gerencie o processo, formal e materialmente, o juiz o faz em constante diálogo com as partes, ouvindo suas opiniões a respeito do caminho a ser trilhado, permitindo que elas participem efetivamente do discurso processual, com poder de influência sobre as possíveis decisões a serem tomadas. Toda a gestão do processo ocorre com a fiel obediência ao princípio do contraditório, inclusive no que concerne ao próprio magistrado ${ }^{50}$.

Neste contexto, a propósito, vale mencionar que as previsões do art. 16 do Novo Código de Processo Civil Francês, do art. $7^{\circ}$ do Código de Processo Civil Português e do $\S$ 139 da Zivilprozessordenung alemã são excelentes exemplos da necessidade de observância do contraditório na condução do processo ${ }^{51}$.

É nesta perspectiva, conforme Mitidiero ${ }^{52}$, que se inclui o órgão jurisdicional, representado pelo juiz, como um dos sujeitos do processo, marcado pela necessidade de cumprir e fazer cumprir o contraditório durante toda a marcha processual, dialogando com as partes. O magistrado encontra-se, portanto, em uma situação que se lhe impõe a direção isonômica do processo, em contínua conversa com as partes, estando sua condução marcada pelos deveres de esclarecimento, prevenção, debate e auxílio para com as partes.

\subsubsection{Pressupostos Lógicos}

Cumpre, aqui, examinar os métodos de decisões utilizados para a solução dos conflitos e a configuração dos poderes atribuídos às partes e ao magistrado no processo, a

\footnotetext{
${ }^{48}$ MITIDIERO, Ibid., p. 63-64.

${ }^{49}$ MITIDIERO, Ibid., p. 64-65.

${ }^{50}$ MITIDIERO, Ibid., p. 65-66.

${ }^{51}$ MITIDIERO, Ibid., p. 66-67.

${ }^{52}$ Ibid., p. 68.
} 
Revista Eletrônica de Direito Processual - REDP.

Rio de Janeiro. Ano 13. Volume 20. Número 2. Maio a Agosto de 2019

Periódico Quadrimestral da Pós-Graduação Stricto Sensu em Direito Processual da UERJ

Patrono: José Carlos Barbosa Moreira (in mem.). ISSN 1982-7636. pp. 47-73 www.redp.uerj.br

fim de constatar o modo pelo qual os modelos de processo isonômico, assimétrico e colaborativo se relacionam com a lógica que serve de substrato para a teoria jurídica que eventualmente lhes serve de suporte ${ }^{53}$.

A forma como os juristas da Idade Média abordavam o direito em geral, possui especial relevo no exame do modelo de processo isonômico. A partir da noção de que o direito se fundava na autoridade dos textos normativos, os juristas trabalhavam com um enunciado textual do qual, após interpretado e debatido, conseguir-se-ia extrair todos os parâmetros para o exercício da prática jurídica. Após a valoração dos textos normativos, passava-se para o caso concreto, o qual centralizava a atenção dos aplicadores do direito no cenário judiciário ${ }^{54}$.

Diversamente ocorreu no âmbito do direito moderno, no qual a estruturação interna do processo é revelada a partir de uma significativa quebra do paradigma que lhe sucedeu (processo isonômico), justificando a configuração do modelo de processo assimétrico ${ }^{55}$.

Como fenômeno cultural que é, o processo da Idade Moderna se deixou influenciar pelo clima cultural da Europa dos Seiscentos, migrando da dialética vigente na Idade Medieval para a estruturação da ciência jurídica a partir da lógica apodítica. Assim, o direito deixa de ser uma controvérsia a ser solucionada pelo jurista por meio da relação "sujeito-sujeito" e passa a ser um objeto que o aplicador do direito precisa conhecer, atrelado a uma relação "sujeito-objeto" - passa-se de uma racionalidade pautada na prática para uma racionalidade teórica, fundada na lógica apodítica, diretamente relacionada ao estudo das ciências exatas ${ }^{56}$.

A concepção lógica que serve de base ao modelo de processo colaborativo, por sua vez, diverge daquela que justifica o modelo assimétrico, acarretando inevitavelmente uma reformulação do processo. A partir de meado dos Novecentos, com o aperfeiçoamento dos estudos sobre a lógica jurídica e a interpretação do direito, restaura-se o seu sentido problemático, o que justifica a busca pela retomada da natureza argumentativa do direito, até então sufocado pela concepção advinda da lógica apodítica ${ }^{57}$.

A renovação da teoria sobre a lógica jurídica, somada ao direito fundamental ao contraditório, logo atribuiu poderes às partes para que pudessem participar da valoração do

\footnotetext{
${ }^{53}$ MITIDIERO, 2015, p. 72-73.

${ }^{54}$ MITIDIERO, Ibid., p. 73.

${ }^{55}$ MITIDIERO, Ibid., p. 78.

${ }^{56}$ MITIDIERO, Ibid., p. 78-79.

${ }^{57}$ MITIDIERO, 2015, p. 85-86.
} 
material jurídico do processo, assegurando-lhes explicitamente o direito de integrar o diálogo processual e influenciar a tomada de decisões ${ }^{58}$.

Neste novo contexto do direito processual civil, o processo assume uma nova estrutura, impondo uma equânime distribuição de tarefas entre todos os integrantes da relação jurídico-processual. No que concerne, notadamente, à questão da interpretação e da aplicação do direito no processo, este novo modelo reclama uma revisão dos brocardos "da mihi factum, dabo tibi ius" 59 e "iura novit curia"60 ${ }^{16}$ característicos do modelo assimétrico ${ }^{61}$.

Para Mitidiero ${ }^{62}$, no entanto, a relativização da máxima "iura novit curia" apenas estará justificada caso se conclua ser ela um problema para o qual a solução traspassa pela atribuição de relevância ao discurso processual estabelecido entre seus sujeitos. É dizer, esta mitigação se legitima se passarmos, no âmbito do processo, de um monólogo - em que a figura central é o magistrado - para um diálogo - de que fazem parte todos os sujeitos processuais.

\subsubsection{Pressupostos Éticos}

Por meio destes pressupostos busca-se examinar os modelos de processo por meio da análise histórica do direito processual civil, mais especificamente em relação à sua constante preocupação com a ética, identificada sob duas perspectivas, da necessidade de resguardo da boa-fé nas relações entre os seus sujeitos, e na obtenção da verdade como resultado do processo ${ }^{63}$.

Nos modelos isonômico e assimétrico, as condutas das partes eram valoradas de acordo com a boa-fé subjetiva, sendo esta exigida apenas das partes, e não do juiz. No tocante ao modelo assimétrico, havia até mesmo a possibilidade de o Estado/Juiz iludir as partes com o escopo de conseguir a verdade, sobretudo porque era dever absoluto delas expor a verdade sobre o que lhes fosse indagado, aplicando-se ao processo uma espécie de moralização platônica ${ }^{64}$.

Já no âmbito do processo colaborativo, que imperiosamente constitui um devido processo legal, a boa-fé é objetivada, havendo uma espécie de acoplamento das

\footnotetext{
${ }^{58}$ MITIDIERO, Ibid., p. 86-87.

${ }^{59}$ Em tradução livre: "dá-me o fato que te darei o direito".

${ }^{60}$ Em tradução livre: "o Tribunal conhece o direito".

${ }^{61}$ MITIDIERO, op. cit., p. 87.

${ }^{62}$ Ibid., p. 90.

${ }^{63}$ MITIDIERO, Ibid., p. 90-91.

${ }^{64}$ MITIDIERO, 2015, p. 91.
} 
perspectivas subjetiva e objetiva, reclamando de todos os sujeitos do processo - até mesmo do magistrado - um comportamento leal em juízo. É neste contexto, aliás, que a boa-fé é prevista no art. $5^{\circ}$ do Código de Processo Civil de $2015^{65}$, tal como no art. 247 da Ley de Enjuiciamiento Civil espanhola.

A boa-fé objetiva, no âmbito do processo civil, tem sua força normativa exteriorizada a partir de deveres impostos aos sujeitos processuais, podendo-se destacar dentre eles (a) a vedação de criar indevidamente posições processuais (proibição do $t u$ quoque); (b) a vedação de comportamento contraditório (nemo potest venire contra factum proprium); (c) a proibição ao abuso de direito (a exemplo da repreensão à utilização do direito de defesa como forma de protelar a efetivação de direito da parte contrária); e (d) a supressio (que corresponde à perda de poderes/faculdades processuais em razão do seu não exercício por certo período $)^{66}$.

No que concerne à problemática relacionada à obtenção da verdade - ainda que a verdade provável, já que sempre lastreada em um juízo de probabilidade -, cumpre assinalar que a sua consideração como um dos objetivos da prova ${ }^{67}$ representa uma condição inarredável para que o processo se desenvolva no sentido de conceder uma decisão justa. Em relação a este problema, duas perspectivas devem ser mais bem analisadas - a possibilidade ou não de produção de provas de ofício pelo juiz, e a atribuição de valor às provas pelo magistrado ${ }^{68}$.

O modelo de processo paritário reservava ao juiz uma função de mero fiscalizador da ordem do processo, vigorando a ideia de que o magistrado não podia interferir na livre disposição conferida às partes para a produção probatória. Neste momento, vigia o sistema da livre apreciação da prova trazida ao processo (MITIDIERO, 2015, p. 94-95).

Contrariamente, no modelo assimétrico, ao magistrado era conferida a direção do processo, sendo-lhe atribuídos amplos poderes para tal mister, figurando como "verdadeiro 'advogado geral das partes"'. Como corolário, reconhecia-se ao juiz a possibilidade de investigar oficialmente os fatos do processo. Aqui vigorava, no âmbito do direito romano, o sistema da livre apreciação da prova, enquanto no processo prussiano tal exame não

\footnotetext{
${ }^{65}$ MITIDIERO, Ibid., p. 91-92.

${ }^{66}$ MITIDIERO, Ibid., p. 93.

${ }^{67}$ Consoante ensina Michele Taruffo (apud MITIDIERO, 2015, p. 93), "a colocação da verdade como objetivo da prova é uma condição necessária para que se coloque a justiça do caso como desiderato do processo".

${ }^{68}$ MITIDIERO, op. cit., p. 93-94.
} 
gozava da mesma liberdade ${ }^{69}$.

$\mathrm{Na}$ contemporaneidade, o papel ativo do juiz na condução do processo, com observância do diálogo, constitui um componente fundamental para o modelo de processo pautado na colaboração. Com a atribuição de iniciativa probatória ao magistrado, supera-se o aspecto meramente individualista do processo influenciado pela cultura francesa dos Oitocentos, e acentua-se a igualdade entre as partes. A colaboração no campo probatório, mercê da iniciativa conferida ao juiz, fica evidenciada ao se impor a este, por força do contraditório, a necessidade de submissão do material colhido à manifestação das partes, às quais se assegura o poder de influenciar a sua valoração para fins de decisão pelo magistrado ${ }^{70}$.

Importante ressaltar que a oficialidade na busca da prova, dentro do processo cooperativo, não permite concluir pela quebra da imparcialidade ou da independência do magistrado, como poderia sugerir a cultura do modelo isonômico, porquanto imparcialidade não se confunde com neutralidade. O juiz neutro se contrapõe ao magistrado ativo, mas ambos podem ser imparciais ${ }^{71}$.

Por fim, para Mitidiero ${ }^{72}$, a valoração da prova, no âmbito do processo colaborativo, não possui condicionantes legais apriorísticas, sendo, neste contexto, reputada livre. O ponto de equilíbrio para esta liberdade situa-se no dever de justificação sobre todo e qualquer juízo de valor efetuado sobre a prova, conforme prevê o art. $371^{73}$ do Código de Processo Civil de 2015.

\subsection{COLABORAÇÃO COMO PRINCÍPIO}

De acordo com Alexy ${ }^{74}$, princípios constituem normas que determinam que algo seja executado na medida mais ampla possível, dentro das possibilidades fático-jurídicas existentes. Princípios, são, por consequência, "mandamentos de otimização", assim definidos por permitirem a sua satisfação em graus distintos e, também, porque a medida

\footnotetext{
${ }^{69}$ MITIDIERO, 2015, p. 95.

${ }^{70}$ MITIDIERO, Ibid., p. 95-96

${ }^{71}$ MITIDIERO, Ibid., p. 96.

72 Ibid., p. 97.

73 Art. 371. O juiz apreciará a prova constante dos autos, independentemente do sujeito que a tiver promovido, e indicará na decisão as razões da formação de seu convencimento.

${ }^{74}$ ALEXY, Robert. Teoria dos Direitos Fundamentais. Tradução de Virgílio Afonso da Silva. São Paulo: Malheiros Editores, 2008. p. 90.
} 
Revista Eletrônica de Direito Processual - REDP.

Rio de Janeiro. Ano 13. Volume 20. Número 2. Maio a Agosto de 2019

Periódico Quadrimestral da Pós-Graduação Stricto Sensu em Direito Processual da UERJ

Patrono: José Carlos Barbosa Moreira (in mem.). ISSN 1982-7636. pp. 47-73

www.redp.uerj.br

adequada de sua observância não depende apenas das possibilidades fáticas, mas também das jurídicas.

Ávila ${ }^{75}$, por sua vez, discorre que os princípios consubstanciam normas “imediatamente finalísticas”, porquanto fixam um "estado de coisas para cuja realização é necessária a adoção de determinados comportamentos". Princípios introduzem uma espécie de "necessidade prática", vale dizer, ordenam a observância de um estado de coisas que apenas será cumprido se o comportamento adequado for empregado ${ }^{76}$.

A partir da ideia de princípio extraída destas premissas teóricas, fica fácil perceber que, além de um modelo processual, a colaboração também deve ser visualizada como um princípio orientador do direito processual, pois constitui algo a ser garantido e efetivado na maior medida possível, dentro das possibilidades fáticas e jurídicas identificadas no processo.

Nas palavras de Mitidiero ${ }^{77}$, a colaboração representa um "estado de coisas" que deve ser realizado. Didier ${ }^{78}$ ressalta que a colaboração constitui um princípio que "informa e qualifica o contraditório".

Conforme lembra Mitidiero $^{79}$, no âmbito da doutrina brasileira, Barbosa Moreira foi quem invocou a colaboração pela primeira vez, ao discorrer sobre a repartição de tarefas no processo entre o juiz e as partes. Numa primeira oportunidade, Barbosa Moreira relaciona a colaboração como "lema" do processo em termos de divisão das iniciativas probatórias. Posteriormente, o processualista cita a colaboração como chave para a solução, em tons harmoniosos, do clássico contraste existente entre os modelos dispositivo e inquisitivo no processo civil.

Em seguida, assinala Mitidiero ${ }^{80}$, Ada Pellegrini Grinover defendeu, ainda que sem maior aprofundamento, uma noção menos individualista e mais dinâmica do princípio do contraditório, o qual reclama a necessidade de a equidistância do magistrado ser corretamente ponderada, em razão da concessão de poderes mais amplos ao juiz, com o escopo de incentivar a real participação das partes no processo e, por corolário, sua cooperação para um processo justo, classificando tais poderes conferidos ao magistrado

\footnotetext{
75 ÁVILA, Humberto. Teoria dos princípios. 16. ed. São Paulo: Malheiros, 2015. p. 63.

76 ÁVILA, 2005, p. 64.

772015 , p. 100.

${ }^{78}$ DIDIER JR., Fredie. O princípio da cooperação: uma apresentação. Revista de Processo, São Paulo, vol. 127, p. 75-79, 2005.

${ }^{79}$ Loc. cit.

${ }^{80}$ Ibid., p. 101.
} 
como "poderes assistenciais".

A despeito destas lembranças iniciais sobre a colaboração, na década de 1980, Mitidiero $^{81}$ assevera que foi Álvaro de Oliveira quem efetivamente introduziu o tema da colaboração entre nós. A partir de seus estudos sobre o contraditório nos idos de 1990, Álvaro de Oliveira sugeriu uma visão cooperativa para o processo civil. Em termos resumidos, sugeriu que o processo fosse conduzido pelo magistrado, mas não de uma posição de superioridade em relação às partes, e sim com base no diálogo sobre o acervo fático-jurídico e o material probatório trazido ao processo, tendo por consectário a mitigação das máximas "iura novit curia" e "da mihi factum, dabo tibo ius". Não bastasse, propôs também um dever de advertência, para que o magistrado informasse as partes sobre eventuais defeitos em suas manifestações, para impedir soluções meramente formais para o processo.

De acordo com Mitidiero ${ }^{82}$, na mesma época, Lúcio Grassi de Gouveia teorizou o princípio da colaboração com base em quatro deveres (esclarecimento, diálogo, prevenção e auxílio) sistematizados por Miguel Teixeira de Souza, examinando a possibilidade de sua similar incidência no âmbito do processo civil brasileiro.

A apropriação - e constante invocação na atualidade, inclusive com previsão no capítulo das normas fundamentais do novo Código de Processo Civil de 2015 (art. $6^{\circ}$ ) - do princípio da colaboração pela doutrina brasileira deve-se, em grande escala, a este aporte teórico. A sua base é extraída da necessidade de um equilíbrio na divisão das tarefas entre cada um dos integrantes do processo. Isto é, seu fundamento decorre não apenas da participação das partes - sinônimo de concretização do contraditório -, mas também na necessidade de observância da igualdade entre os sujeitos do processo ${ }^{83}$.

O objetivo da colaboração, considerada como princípio, consiste em estruturar o processo de forma a permitir que se alcance, em tempo razoável, uma decisão de mérito justa e efetiva, conforme, aliás, prevê o art. $6^{\circ}$ do Código de Processo Civil. Necessita-se, portanto, empregar o diálogo como ferramenta essencial para condução do processo, dando-se prioridade para decisões materiais, apurar a verdade sobre as manifestações das partes, para que se possa aplicar corretamente o direito, e fazer uso das técnicas executivas

\footnotetext{
${ }^{81}$ Ibid., p. 101-102.

82 2015, p. 102.

${ }^{83}$ MITIDIERO, Ibid., p. 102-103.
} 
que permitam dar melhor efetividade aos direitos reconhecidos no processo ${ }^{84}$.

Neste contexto, assinala Mitidiero ${ }^{85}$, deve ser ressaltado que a cooperação no processo "não importa em renúncia ao primado da autorresponsabilização das partes no processo". Vale dizer, a colaboração não constitui instrumento apto a derrogar o princípio dispositivo ou, até mesmo, suprimir o princípio da liberdade que the confere respaldo normativo. Os deveres que informam o princípio da colaboração (diálogo, esclarecimento, prevenção e auxílio) constituem meios para viabilizar uma decisão justa, mas que não maculam a responsabilidade das partes no tocante à necessidade de se desincumbirem de seus ônus processuais. O princípio da colaboração, por exemplo, não impede que uma parte insista em um comportamento inapropriado, ainda que esclarecida sobre suas consequências pelo magistrado. O que se promove, a partir deste princípio, é a prioridade desde que possível - da decisão de mérito sobre a meramente processual, impondo-se, mercê disso, a relativização do binômio "direito-processo".

Assim, a colaboração, encarada como princípio, determina que, na maior medida possível, dentro das possibilidades fáticas e jurídicas existentes, seja observado o diálogo entre os sujeitos processuais, para que se conduza o processo a uma solução de mérito, configurando a respectiva decisão judicial o resultado da valoração dos argumentos deduzidos pelas partes em suas manifestações.

\section{DEVER DE FUNDAMENTAÇÃO DAS DECISÕES JUDICIAIS E O PAPEL DO PRINCÍPIO DA COLABORAÇÃO}

Inicialmente, assevere-se que a expressão "decisão judicial" a que se refere o presente trabalho deve ser interpretada em seu sentido amplo, pois diz respeito a todos os comandos judiciais exarados pelo magistrado, tendentes a resolver as questões formais e materiais do processo. Ou seja, a expressão refere-se, aqui, indistintamente à decisão interlocutória, à sentença ou ao acórdão, nos mesmos termos em que empregada pelo art. $489, \S 1^{\circ}$, do Código de Processo Civil.

\subsection{ALCANCE DO DEVER DE FUNDAMENTAÇÃO DAS DECISÕES JUDICIAIS}

\footnotetext{
${ }^{84}$ MITIDIERO, Ibid., p. 103-104.

${ }^{85}$ Ibid., p. 105.
} 
Revista Eletrônica de Direito Processual - REDP.

Rio de Janeiro. Ano 13. Volume 20. Número 2. Maio a Agosto de 2019

Periódico Quadrimestral da Pós-Graduação Stricto Sensu em Direito Processual da UERJ

Patrono: José Carlos Barbosa Moreira (in mem.). ISSN 1982-7636. pp. 47-73 www.redp.uerj.br

Conforme ressaltam Oliveira e Kfouri Neto ${ }^{86}$, atentando-se para os objetivos de um

Estado Democrático de Direito, o dever de fundamentação das decisões judiciais exsurge como uma garantia democrática de que nenhum indivíduo terá seus interesses atingidos por uma manifestação judicial desprovida dos motivos que levaram à sua prolação.

É nesta perspectiva que Moreira ${ }^{87}$ defende a fundamentação das decisões judiciais como expressão do Estado de Direito, assentada na contemporaneidade a partir da Revolução Francesa. De acordo com Moreira (1988, p. 83-95) $)^{88}$, o dever de fundamentação das decisões judiciais possui um duplo aspecto - endoprocessual e extraprocessual - que o justificam. Primeiramente, sob o aspecto endoprocessual, a fundamentação das decisões judiciais visa a permitir que as partes tenham conhecimento das razões da decisão, para que possam contra ela se insurgir pelas vias processuais adequadas. Segundo, sob o ponto de vista extraprocessual, a motivação das decisões destina-se a viabilizar o controle social da atuação do Poder Judiciário.

Neste contexto, seguindo o rumo da Declaração Universal dos Direitos Humanos de 1948 (art. 10) e da Convenção Americana sobre Direitos Humanos de 1969 (art. 66), a Constituição da República assegura, em seu art. 93, inc. IX, que todas as decisões do Poder Judiciário serão devidamente fundamentadas, sob pena de nulidade ${ }^{89}$.

Ao interpretar a redação do art. 93, inc. IX, da Constituição da República, Guerra ${ }^{90}$ explica que o constituinte não estabeleceu, neste dispositivo, de forma suficiente, os parâmetros para que se possa identificar quando a decisão judicial será reputada fundamentada ou não. Em razão disso, essa constatação deve ocorrer com base em outros dados, ditos "contextuais".

Ainda de acordo com Guerra ${ }^{91}$, inúmeros dados contextuais permitem assimilar o sentido conferido a um texto normativo. Mas, afigura-se evidente, a prioridade deve ser

86 OLIVEIRA, Francisco Cardozo; KFOURI NETO, Miguel. O Alcance da Fundamentação da Decisão Judicial na Relação Entre Fatos e Normas segundo o Inciso I do $\S 1^{\circ}$ do Artigo 489 do Novo Código de Processo Civil. In VASCONCELLOS, Fernando Andreoni; ALBERTO, Tiago Gagliano Pinto (organ.). O dever de fundamentação no novo CPC: análises em torno do artigo 489. Rio de Janeiro: Lumen Juris, 2015. p. 203-232.

${ }^{87}$ MOREIRA, José Carlos Barbosa. A motivação das decisões judiciais como garantia inerente ao Estado de Direito. In Temas de Direito Processual. 2a . ed. São Paulo: Editora Saraiva, 1988. p. 83-95.

${ }^{88}$ Loc. cit.

${ }^{89}$ OLIVEIRA e KFOURI NETO, 2015, p. 203-232.

${ }^{90}$ GUERRA, Marcelo Lima. Notas sobre o Dever Constitucional de Fundamentar as Decisões Judiciais. In: FUX, Luiz; NERY JR., Nelson; e WAMBIER, Teresa Arruda Alvim (Coord.). Processo e Constituição: estudos em homenagem ao professor José Carlos Barbosa Moreira. São Paulo: Editora Revista dos Tribunais, 2006. p. 517-541.

${ }^{91}$ Loc. cit. 
Revista Eletrônica de Direito Processual - REDP.

Rio de Janeiro. Ano 13. Volume 20. Número 2. Maio a Agosto de 2019

Periódico Quadrimestral da Pós-Graduação Stricto Sensu em Direito Processual da UERJ

Patrono: José Carlos Barbosa Moreira (in mem.). ISSN 1982-7636. pp. 47-73

www.redp.uerj.br

atribuída àqueles emanados do próprio legislador, ou seja, identificados como originários do próprio ordenamento, como forma de resguardar o "postulado de racionalidade do legislador", manifestado como reclamo de coerência.

Ao que parece, com o escopo de oferecer subsídios para o cumprimento da exigência constitucional de fundamentação das decisões judiciais, o novo Código de Processo Civil de 2015, em seu art. 489, $\S 1^{\mathrm{o} 92}$, procurou estabelecer os parâmetros para que se possa identificar uma decisão não fundamentada.

Oportunamente, vale ressaltar que esta metodologia incorporada ao novo Digesto Processual Civil está de acordo com o proposto por Guerra ${ }^{93}$, para o qual, mercê da complexidade que envolve a questão da fundamentação das decisões judiciais, diante do problema do regresso ao infinito na obtenção das justificativas suficientes para motivar uma decisão, pode-se chegar a uma solução plausível estabelecendo-se não o que se considera por decisão suficientemente fundamentada, mas, ao contrário, o que se reputa uma decisão não fundamentada, concluindo caber ao magistrado, sob esta ótica, evitar a prolação de decisões "equivocadamente fundamentadas".

Comentando o art. 489, $\S 1^{\circ}$, do Código de Processo Civil de 2015, Marinoni, Arenhart e Mitidiero ${ }^{94}$ assinalam que ele tem por objetivo evitar as denominadas decisões genéricas, uma vez que a fundamentação adequada, nos termos reclamados pelo texto constitucional, exige a individualização das normas incidentes ao caso concreto.

Rejeita-se, por isso, conforme Marinoni, Arenhart e Mitidiero ${ }^{95}$, a mera indicação, paráfrase ou reprodução de dispositivos legais (CPC, art. 489, § $\left.1^{\circ}, \mathrm{I}\right)$, ou então a simples citação de termos vagos, como cláusulas gerais e conceitos jurídicos indeterminados (CPC, art. $489, \S 1^{\circ}$, II). Também não se permite ao juiz a utilização de fundamentos que serviriam para justificar qualquer outra decisão (CPC, art. 489, § $1^{\circ}$, III), exigindo-se a

\footnotetext{
92 Art. 489. [...] § 10 Não se considera fundamentada qualquer decisão judicial, seja ela interlocutória, sentença ou acórdão, que: I - se limitar à indicação, à reprodução ou à paráfrase de ato normativo, sem explicar sua relação com a causa ou a questão decidida; II - empregar conceitos jurídicos indeterminados, sem explicar o motivo concreto de sua incidência no caso; III - invocar motivos que se prestariam a justificar qualquer outra decisão; IV - não enfrentar todos os argumentos deduzidos no processo capazes de, em tese, infirmar a conclusão adotada pelo julgador; V - se limitar a invocar precedente ou enunciado de súmula, sem identificar seus fundamentos determinantes nem demonstrar que o caso sob julgamento se ajusta àqueles fundamentos; VI - deixar de seguir enunciado de súmula, jurisprudência ou precedente invocado pela parte, sem demonstrar a existência de distinção no caso em julgamento ou a superação do entendimento.

${ }^{93}$ Op. cit., p. 517-541.

${ }^{94}$ MARINONI, Luiz Guilherme; ARENHART, Sérgio Cruz; MITIDIERO, Daniel. Novo curso de processo civil: tutela dos direitos mediante procedimento comum. v. II. 2. ed. rev. atual. e ampl. São Paulo: Editora Revista dos Tribunais, 2016. p. 454.

${ }^{95}$ 2016, p. 454.
} 
devida motivação, ainda, acerca da identidade ou semelhança, quando invocar a aplicação de precedente ou enunciado de súmula (CPC, art. 489, § $1^{\circ}$, V), ou mesmo a indicação das razões que levam à distinção destes com o caso concreto, a fim de negar sua incidência (CPC, art. 489, § $\left.1^{\circ}, \mathrm{VI}\right)$.

\subsection{PRINCÍPIO DA COLABORAÇÃO E SUA INFLUÊNCIA SOBRE A FUNDAMENTAÇÃO DAS DECISÕES JUDICIAIS}

No que interessa ao objeto deste trabalho, o inc. IV do $\S 1^{\circ}$ do art. 489 do Código de Processo Civil prescreve que não se considera fundamentada qualquer decisão judicial que "não enfrentar todos os argumentos deduzidos no processo capazes de, em tese, infirmar a conclusão adotada pelo julgador".

Esta previsão ressalta o caráter cooperativo do processo civil, assim estruturado especialmente a partir do novo Código de Processo Civil de 2015 (art. 6º), pois constitui decorrência direta da necessidade de diálogo entre os sujeitos do processo - partes e juiz ao longo de sua tramitação.

Essa necessidade de diálogo se mostra ainda mais evidente a partir do exame dos arts. $9^{\circ}$ e 10 do novo Digesto Processual Civil, os quais estabelecem que não será proferida decisão contra qualquer das partes sem que ela seja previamente ouvida, não podendo o juiz decidir, também, em nenhum grau de jurisdição, com base em fundamento acerca do qual não se tenha oportunizado a prévia manifestação das partes, mesmo sendo matéria em relação à qual ele deva conhecer de ofício.

Abordando o inc. IV do $\S 1^{\circ}$ do art. 489 do Código de Processo Civil de 2015, Marinoni, Arenhart e Mitidiero ${ }^{96}$ asseveram que ele só pode ser corretamente interpretado a partir da nova roupagem atribuída ao contraditório. No tempo em que se concebia este instituto como aplicável apenas às partes, era válida a conclusão de que a fundamentação das decisões judiciais não tinha como parâmetro para verificação da sua adequação a atividade desempenhada pelas partes, bastando ao juiz evidenciar quais os motivos que justificavam o dispositivo. Era suficiente, então, a inexistência de contradição entre as proposições da decisão.

Atualmente, no entanto, com os novos contornos conferidos ao contraditório, esta

\footnotetext{
${ }^{96}$ Ibid., p. 455.
} 
perspectiva foi superada. A partir da noção de que o contraditório corresponde ao direito de influenciar as manifestações judiciais (cf. CPC/2015, arts. $7^{\circ}, 9^{\circ}$ e 10), mostra-se irrefutável a percepção de que ele pressupõe o cumprimento de um dever de debate, compreendidos os deveres de consulta, diálogo e consideração. Nesta ordem, apresenta-se clara a necessidade de o magistrado rebater, em sua decisão, os argumentos deduzidos pelas partes durante o diálogo processual, e capazes de influenciar sua conclusão ${ }^{97}$.

Não se mostra mais suficiente, portanto, a ausência de contradição entre as proposições da decisão. A adequada fundamentação, hoje, pressupõe o atendimento a um critério extrínseco - a abordagem dos argumentos apresentados pelas partes durante suas manifestações ao longo do trâmite processual ${ }^{98}$.

É de todo relevante, no entanto, enfatizar que o art. 489, § $1^{\circ}$, inc. IV, do Código de Processo Civil de 2015 não tem por escopo impor ao órgão jurisdicional o dever de examinar e rechaçar todo e qualquer argumento apresentado pelas partes do processo. $\mathrm{O}$ dever a ser observado diz respeito ao diálogo entre os sujeitos processuais - juiz e partes acerca dos argumentos que podem, por si sós, ensejar o acolhimento ou rejeição de um pedido - ou o conhecimento, não conhecimento, provimento ou não provimento de um recurso. Os demais argumentos apenas serão abordados pelo magistrado com a finalidade de evidenciar que eles não têm aptidão para determinar a adoção de conclusão distinta daquela a que chegou o órgão jurisdicional ${ }^{99}$.

Como ressaltam Marinoni, Arenhart e Mitidiero ${ }^{100}$, nem juízes, nem desembargadores e tampouco Ministros possuem o dever de rebater todos os argumentos apresentados pelas partes. O dever imposto pela norma diz respeito ao diálogo acerca dos argumentos relevantes, ou seja, daqueles aptos a modificar a conclusão do órgão julgador.

Por fim, importante destacar, como o fazem Didier e Peixoto ${ }^{101}$, que, ao lado do dever atribuído ao órgão julgador, de enfrentamento dos argumentos deduzidos pelas partes, há, também, o dever de estas formularem suas pretensões de forma fundamentada,

\footnotetext{
${ }^{97}$ MARINONI, ARENHART e MITIDIERO, 2016, p. 456.

${ }^{98}$ MARINONI, ARENHART e MITIDIERO, loc. cit.

${ }^{99}$ MARINONI, ARENHART e MITIDIERO, loc. cit.

${ }^{100}$ Loc. cit.

${ }^{101}$ DIDIER JR, Fredie; PEIXOTO, Ravi. O art. 489, $\$ 1^{\circ}$, do CPC e a sua incidência na postulação dos sujeitos processuais - um precedente do STJ. Revista Jurídica da Escola Superior de Advocacia da OABPR / Ordem dos Advogados do Brasil. Seção do Paraná; Escola Superior de Advocacia; Coordenação Científica de Fernando Previdi Motta, Graciela I. Marins, v.3, n.1 (maio. 2018), p. 85-97, Curitiba: OABPR, 2018.
} 
Revista Eletrônica de Direito Processual - REDP.

Rio de Janeiro. Ano 13. Volume 20. Número 2. Maio a Agosto de 2019

Periódico Quadrimestral da Pós-Graduação Stricto Sensu em Direito Processual da UERJ

Patrono: José Carlos Barbosa Moreira (in mem.). ISSN 1982-7636. pp. 47-73

www.redp.uerj.br

justificando analiticamente cada uma de suas postulações, a fim de permitir que, no momento da decisão, se identifique com precisão cada argumento a ser apreciado.

\section{CONCLUSÃO}

Estabeleceu-se como problema a análise da relação que pode ser estabelecida entre a fundamentação das decisões judiciais e a necessidade de observância do dever de colaboração.

Nesse sentido, ficou assentado, ao longo do trabalho, a necessidade de adoção por todos os sujeitos processuais de uma postura dialética, primando pelo diálogo a fim de viabilizar a condução do processo, em tempo razoável, rumo a uma decisão de mérito justa e efetiva, como resultado do debate realizado ao longo do trâmite processual.

Nesta perspectiva, em linhas conclusivas, pode ser afirmado que, na atual fase da ciência processual civil, correspondente ao que se pode denominar de instrumentalismo constitucional, a colaboração constitui um modelo e, ao mesmo tempo, um mandado de otimização que privilegia o diálogo entre os sujeitos da relação jurídico-processual.

A colaboração, elencada como norma fundamental do processo civil pelo Digesto Processual de 2015 (art. $6^{\circ}$ ), tem por escopo atribuir novos contornos ao princípio do contraditório, impondo ao juiz o dever de conduzir o processo em constante diálogo com as partes. Deste modo, a direção do processo, no modelo cooperativo, impõe ao magistrado a necessária observância dos deveres de esclarecimento, prevenção, debate e auxílio para com as partes.

Como corolário, o cumprimento do dever de motivação das decisões judiciais sobretudo em razão da previsão do art. 489, $\S 1^{\circ}$, inc. IV, do Código de Processo Civil de 2015 - traspassa, necessariamente, pela observância da colaboração, pois, para formular uma fundamentação adequada, o magistrado precisa examinar e justificar o acolhimento ou a recusa dos argumentos deduzidos pelas partes, desde que capazes de infirmar a sua conclusão. A correção da fundamentação das decisões judiciais dependerá do quanto as partes estejam comprometidas com argumentos fundamentados e com a solução justa da lide. 


\section{REFERÊNCIAS}

ALEXY, Robert. Teoria dos Direitos Fundamentais. Tradução de Virgílio Afonso da Silva. São Paulo: Malheiros Editores, 2008.

ÁVILA, Humberto. Teoria dos princípios. 16. ed. São Paulo: Malheiros, 2015.

BEDAQUE, José Roberto dos Santos. Direito e Processo: influência do direito material sobre o processo. 2. ed. São Paulo: Malheiros Editores, 1995.

BONAVIDES, Paulo. Teoria Constitucional da Democracia Participativa. São Paulo: Malheiros Editores, 2001.

CAMBI, Eduardo. Neoconstitucionalismo e Neoprocessualismo. In: FUX, Luiz; NERY JR., Nelson; e WAMBIER, Teresa Arruda Alvim (Coord.). Processo e Constituição: estudos em homenagem ao professor José Carlos Barbosa Moreira. São Paulo: Editora Revista dos Tribunais, 2006. p. 662-683.

CANOTILHO, José Joaquim Gomes. Direito Constitucional. 6. ed. Coimbra: Almedina, 1995.

DIDIER JR., Fredie. O princípio da cooperação: uma apresentação. Revista de Processo, São Paulo, vol. 127, p. 75-79, 2005.

; PEIXOTO, Ravi. O art. 489, $\$ 1^{\circ}$, do CPC e a sua incidência na postulação dos sujeitos processuais - um precedente do STJ. Revista Jurídica da Escola Superior de Advocacia da OAB-PR / Ordem dos Advogados do Brasil. Seção do Paraná; Escola Superior de Advocacia; Coordenação Científica de Fernando Previdi Motta, Graciela I. Marins, v.3, n.1 (maio. 2018), p. 85-97, Curitiba: OABPR, 2018.

DINAMARCO, Cândido Rangel. A Instrumentalidade do Processo. 5. ed. rev. e atual. São Paulo: Malheiros Editores, 1996.

Fundamentos do Processo Civil Moderno. São Paulo: Editora Revista dos Tribunais, 1986.

A Reforma do Código de Processo Civil. São Paulo: Malheiros Editores, 1995. ; CARRILHO LOPES, Bruno Vasconcelos. Teoria Geral do Novo Processo Civil. São Paulo: Malheiros Editores, 2016.

GUERRA, Marcelo Lima. Notas sobre o Dever Constitucional de Fundamentar as Decisões Judiciais. In: FUX, Luiz; NERY JR., Nelson; e WAMBIER, Teresa Arruda 
Alvim (Coord.). Processo e Constituição: estudos em homenagem ao professor

José Carlos Barbosa Moreira. São Paulo: Editora Revista dos Tribunais, 2006. p. $517-541$.

LORENZETTI, Ricardo Luis. Teoria da Decisão Judicial - Fundamentos de Direito. Tradução de Bruno Miragem e Cláudia Lima Marques. São Paulo: Editora Revista dos Tribunais, 2009.

MARINONI, Luiz Guilherme; ARENHART, Sérgio Cruz; MITIDIERO, Daniel. Novo curso de processo civil: tutela dos direitos mediante procedimento comum. v. II. 2. ed. rev. atual. e ampl. São Paulo: Editora Revista dos Tribunais, 2016.

MITIDIERO, Daniel. Colaboração no Processo Civil - Pressupostos Sociais, Lógicos e Éticos. 3. ed. São Paulo: Editora Revista dos Tribunais, 2015.

MOREIRA, José Carlos Barbosa. O problema da "divisão de trabalho" entre o juiz e as partes: aspectos terminológicos. Revista de Processo, São Paulo, vol. 41, p. 8-14, 1988.

A motivação das decisões judiciais como garantia inerente ao Estado de Direito. In Temas de Direito Processual. 2a . ed. São Paulo: Editora Saraiva, 1988.

OLIVEIRA, Francisco Cardozo; KFOURI NETO, Miguel. O Alcance da Fundamentação da Decisão Judicial na Relação Entre Fatos e Normas segundo o Inciso I do $\S 1^{\circ}$ do Artigo 489 do Novo Código de Processo Civil. In VASCONCELLOS, Fernando Andreoni; ALBERTO, Tiago Gagliano Pinto (Organ.). O dever de fundamentação no novo CPC: análises em torno do artigo 489. Rio de Janeiro: Lumen Juris, 2015. p. 203-232. 